\title{
Non-Contact Determination of Antisymmetric Plate Wave Velocity in Ceramic Matrix Composites
}

Harold E. Kautz

Lewis Research Center

Cleveland, Ohio

February 1996

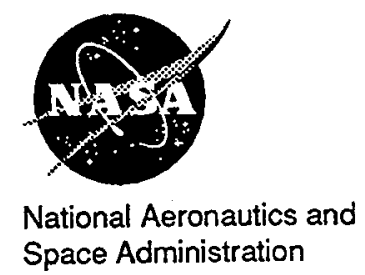


$\checkmark$ 


\title{
NONCONTACT DETERMINATION OF ANTISYMMETRIC PLATE WAVE VELOCITY IN CERAMIC MATRIX COMPOSITES
}

\author{
Harold E. Kautz \\ National Aeronautics and Space Administration \\ Lewis Research Center \\ Cleveland, Ohio 44135
}

\begin{abstract}
A $13 \mathrm{~mJ}$ NdYAG $1064 \mathrm{~nm}, 4 \mathrm{~ns}$, laser pulse was employed to produce ultrasonic plate waves in 20 percent porous $\mathrm{SiC} / \mathrm{SiC}$ composite tensile specimens of three different architectures. An air coupled $0.5 \mathrm{MHz}$ transducer was used to detect and collect the waveforms which contained first antisymmetric plate wave pulses for determining the shear wave velocity (VS). These results were compared to VS values determined on the same specimens with $0.5 \mathrm{MHz}$ ultrasonic transducers with contact coupling. Averages of four noncontact determinations on each of 18 specimens were compared to averages of four contact values. The noncontact VS's fall in the same range as the contact. The standard deviations for the noncontact VS's averaged 2.8 percent. The standard deviations for the contact measurements averaged 2.3 percent, indicating similar reproducibility.

Repeated laser pulsing at the same location always lead to deterioration of the ultrasonic signal. The signal would recover in about $24 \mathrm{hr}$ in air however, indicating that no permanent damage was produced.
\end{abstract}

\section{INTRODUCTION}

High temperature materials are of increasing importance in development of more efficient engines and components for the aeronautics industry. In particular, ceramic matrix composite (CMC) and metal matrix composite (MMC) structures are under active development for these applications [1].

The acousto-ultrasonic (AU) method has been shown to be useful for assessing mechanical properties in composite structures [1-8]. In particular, plate wave analysis has been shown to be useful $[1,9,10]$ for characterizing composites in terms of the stiffness moduli. It is desirable to monitor changes in mechanical properties which occur during thermomechanical testing. It is also desirable to monitor the health of components whose geometry or position make them not readily assessable to conventional ultrasonic probes. For these and other similar applications it would be useful to apply AU by means that do not require direct coupling to the surface of a subject to be interrogated [11].

The use of a laser as a remote ultrasonic input source and also as an ultrasound detector have been under investigation for a number of years [12-15]. The use of an ultrasonic transducer, coupled through an air gap has also been under study [16-17].

It has so far been the experience in this laboratory that the use of a laser as an ultrasonic input medium has been more successful than as an output device. On the other hand, we have been more successful using an air coupled piezoelectric transducer as an output device than as input. For this reason we have studied the combination laser in air coupled transducer out. This work describes the use of the pulsed NdYAG laser as the input ultrasonic source in conjunction with an air coupled transducer as the detector.

\section{EXPERIMENTAL}

Figure 1 illustrates the experimental arrangement for doing laser in - air transducer out on $\mathrm{SiC} / \mathrm{SiC}$ composite tensile specimens. The NdYAG pulse is directed downward by a $90^{\circ}$ infrared prism to the top, but at the edge of one end of the specimen. The laser was single pulsed at approximately $13 \mathrm{~mJ}$ per pulse as measured by the energy sensor before passing through the prism. The prism attenuated 15 percent of the energy of the beam. The 
energy sensor also provided an output trigger for the waveform time delay synthesizer.

The air coupled piezoelectric transducer was broadband and centered nominally at $0.5 \mathrm{MHz}$. It was coupled to the air through a buffer which was shaped to focus the ultrasound 2 in. beyond its surface. We have shown that, for the case of CMC specimens of the present geometry the frequency range is very much dominated by the lowest antisymmetric plate mode $[2,10]$. This mode, in turn, is sensitive to shear and flexure moduli [2], and, in $\mathrm{SiC} /$ Reaction bonded SN composite it has been shown sensitive to fiber/matrix interfacial shear strength [9].

Since the laser beam was directed at one end of the specimen the stimulated ultrasonic signal left the site in only one direction, thus simplifying the identification of the subsequent reflections of the opposite ends by the lowest antisymmetric plate wave pulse.

Figure 2 illustrates the experimental arrangement for doing conventional contact measurements on the $\mathrm{SiC} / \mathrm{SiC}$ composite tensile specimens. In this case, broadband piezoelectric transducers, with $0.5 \mathrm{MHz}$ center frequency, are coupled to the surface of the specimen through elastomer pads. The arrival time at the receiving transducer of the lowest antisymmetric plate mode pulse is regressed against the transducer separation $\mathrm{s}$, for several values of $s$. The slope of the regression curve yields VS. This is discussed in detail elsewhere [10].

\section{CMC MATERIAL USED}

Six specimens of each of 3 layups, $0 / 90, \pm 45$, and $[0 /+45 / 90 /-45]_{S}$, of approximately 20 percent porous $\mathrm{SiC} / \mathrm{SiC}$ were studied. They had 40 percent fiber fraction. Each layup was in eight ply panels cut into $0.5^{\prime \prime} \times 6.0^{\prime \prime}$ rectangular bars with thickness 0.25 to $0.29 \mathrm{~cm}$. After being cut into rectangular bars they were treated with a seal coating.

\section{DETERMINATION OF SHEAR WAVE VELOCITY, VS}

Figure 3 shows a typical laser - air waveform collected from a SiC/SiC tensile specimen with the time synthesizer trigger delay set at zero. With no delay, a transient effect, possibly electronic sometimes dominates the early part of the waveform. In the case of figure 3 this occurs within the first $25 \mu \mathrm{s}$ of this $500 \mu \mathrm{s}$ record. The first of the antisymmetric plate wave pulses generated by the laser comes at about $154 \mu \mathrm{s}$. If we take the velocity of sound in air as $340 \mathrm{~m} / \mathrm{s}$ [18], then the time to cross the $2 \mathrm{in}$. from the specimen surface to the focussed transducer is $149 \mu \mathrm{s}$. Thus the air gap crossing accounts for most of the long delay.

Figure 4 is similar to figure 3 except that the digitizer trigger delay is set at $125 \mu \mathrm{s}$ and the digitized record is $200 \mu \mathrm{s}$. This waveform contains four prominent pulses which are the lowest antisymmetric plate wave after consecutive reflections off of the ends of the specimen. Figure 5 shows the interpretation of the path history of these pulses. The pulses $a, b, c$, and $d$ in figure 4 correspond, respectively, to the times $t_{a}, t_{b}, t_{c}$, and $t_{d}$ in figure 5 that the lowest antisymmetric mode signal passes the place along the specimen where the air coupled transducer is focussed.

During the time intervals $t_{c}-t_{a}$ and $t_{d}-t_{b}$ the lowest antisymmetric mode signal makes two crossings of

$$
\mathrm{VS}=2 \mathrm{~L} /\left(\mathrm{t}_{\mathrm{c}}-\mathrm{t}_{\mathrm{a}}\right)=2 \mathrm{~L} /\left(\mathrm{t}_{\mathrm{d}}-\mathrm{t}_{\mathrm{b}}\right)
$$

the length, $\mathrm{L}$, of the specimen. The velocity, VS, can be calculated from:

So there are two values that can be compared for consistency.

The pulse times are determined in the same manner for contact measurements which are described elsewhere [10]. The signal is frequency filtered for the pulses. The amplitude spectrum of the figure 4 signal is shown in figure 6. This shows that the 0.32 to $0.5 \mathrm{MHz}$ portion, which is the sensitive range of the air coupled transducer, is 
dominant. A bandpass filter of 0.4 to $0.5 \mathrm{MHz}$ is chosen for the calculation. For the present specimen material and configuration this is the important range for the pulses.

The specimen can be rotated end for end and also top for bottom for a total of four orientations with the same geometry. This is done to obtain four values of VS from equation (1). Averages and standard deviations of VS are reported from these four values.

Figures 7 and 8 show, respectively, the time domain and magnitude spectrum of a contact measurement signal collected on the same specimen as shown in figures 4 and 6.

For the noncontact case discussed above all pulse arrivals $t_{a}, t_{b}, t_{c}$, and $t_{d}$, for a given VS calculation were taken from the same waveform record. The energy sensor trigger was not precise enough to reliably compare arrival times from different records. However in the contact measurements a pulser trigger was used. This is sufficiently precise that individual pulses could be collected in a record and compared with others for VS determination.

Any differences between the two measurements are within the range of validity of the VS values. The noncontact VS is an average over the total length of the specimen. The contact VS is an average over the positions of the receiving transducer during data collection. If the specimen VS is nonuniform these could be different. However, in the present case, any nonuniformity was not detected.

\section{RESULTS AND DISCUSSION}

The noncontact average VS's are plotted against the contact average VSs in figure 9 . The standard deviation of the 18 sets of velocities were determined. The average for the non-contact data is 2.8 and for the contact it is 2.3 percent, indicating very similar reproducibility. Standard deviation bars are not plotted in figure 9 so as to increase visualization of the correlation between the contact and noncontact VS. The trend from low to high VS would be less impressive with the standard deviations plotted. The correlation coefficient for linear regression of these data pairs is $R^{2}=0.32$. The important result is that this noncontact technique gives results for VS that are as reliable as the conventional technique with contact coupled transducers.

It was observed that repeated laser pulsing at the same location always leads to deterioration of the ultrasonic signal. However, the signal would recover in about $24 \mathrm{hr}$ in air, indicating that no permanent damage was produced. The mechanism of this deterioration is thought to be evaporation of a regenerating surface layer, possibly water vapor, that is essential in transforming the laser energy to ultrasonic energy. Attempts were made to accelerate the recovery of the signal by applying water. But this was unsuccessful.

\section{CONCLUSIONS}

The laser in - air coupled out system has been shown capable of providing data as accurate as with contact coupled transducers in the case of determining the velocity associated with the lowest antisymmetric plate mode for $\mathrm{SiC} / \mathrm{SiC}$ ceramic matrix composites.

\section{RECOMMENDATIONS}

It would be useful to explore the nature of the mechanism which converts laser pulse energy to ultrasonic energy in this system. With this information it may be possible to devise a technique for repeated laser pulsing without ultrasonic signal deterioration.

It would also be useful to do laser - air experiments at significantly higher laser energies. Higher laser energy will produce larger ultrasonic signals which will, in turn, allow accurate determination of other acoustoultrasonic parameters.

A further value of higher laser energies is to determine the damage threshold for typical CMC systems of aeronautical interest. 


\section{REFERENCES}

1. 1st - 5th Annual HITEMP Reviews, 1988 - 1992, NASA CP-10025, 10039, 10051, 10082, and 10104.

2. Tang, B. and Henneke II, E.G., "Long Wavelength Approximation for Lamb Wave Characterization of Composite Laminates," Res. Nondestr. Eval., 1:51, (1989).

3. Vary, A. and Bowles, K.J., "Use of Ultrasonic Acoustic Techniques for Nondestructive Evaluation of Fiber Composite Strength," Proceeding of 33rd Annual conference, SPI, New York, 1978, Section 24-A, pp. 1-5.

4. Williams, J.H., Jr, Yuce, H., and Lee, S.S., "Ultrasonic and Mechanical Characterizations of Fatigue States of Graphite Epoxy Composite Laminates," Mater. Eval., 40:560, (1982).

5. Kautz, H.E., "Ultrasonic Evaluation of Mechanical Properties of, Thick, Multilayered, Filament-Wound Composites," Mater. Eval., 45:1404, (1987).

6. Kautz, H.E. and Lerch, B.A., "Preliminary Investigation of Acousto-Ultrasonic Evaluation of Metal-Matrix Composite Specimens," Mater. Eval., 49:607 (1991).

7. Vary, A., "Acoustoultrasonics," NonDestructive Testing of Fibre-Reinforced Plastic Composites, Vol. 2, Chap. 1, pp. 1-54, Elsevier Science Publishing Co. London, New York, 1990.

8. Henneke, E.G., Jr, "Ultrasonic Nondestructive Evaluation of Advanced Composites," NonDestructive Testing of Fibre-Reinforced Plastic Composites, Vol. 2, Chap. 2, pp. 55-160, Elsevier Science Publishing Co. London, New York, 1990.

9. Kautz, H.E. and Bhatt, R.T., "Ultrasonic Velocity Technique for Monitoring Property Changes in FiberReinforced Ceramic Matrix Composites," 15th Annual Conference on Composites and Advanced Ceramics, American Ceramic Society, Cocoa Beach, Florida, January 13-16, 1991, NASA TM-103806 (1991).

10. Kautz, H.E., "Detecting Lamb Waves with Broad-Band Acousto-Ultrasonic Signals in Composite Structures," Research in Nondestructive Evaluation, 4:151, (1992), NASA TM-105557 (1992).

11. Alers, G.A. and Wadley, H.N.G., "Noncontact Ultrasonics Applied to Sensor Needs for Hot Metal Processing in the Steel Industry," Proc. of Conf. on Intelligent Processing of Materials and Advanced Sensors, TMS Warrendale, 1987.

12. "Acousto-Ultrasonic Nondestructive Evaluation of Materials Using Laser Beam Generation and Detection," R.D. Huber and R.E. Green, NASA CR-185282, (1990).

13. Scruby, C.B. and Drain, L.E., Laser Ultrasonics, Adam Hilger, New York, 1990.

14. Monchalin, J.P., "Optical Detection of Ultrasound," IEEE Trans. UFFC-33(5), pp. 485-499, (1986).

15. Kautz, H.E., "New Acousto-Ultrasonic Techniques Applied to Aerospace Materials, Conference on NonDestructive Testing and Evaluation for Manufacturing and Construction, University of Illinois, Urbana, Illinois, (1988), NASA TM-101299.

16. Nondestructive Testing Handbook,Vol. 7, Ultrasonic Testing, Second Ed., ASNT, 1991, pp. 320-325.

17. Safaeinili, A., Lobkis, O.I., and Chimenti, D.E., "Air-Coupled Ultrasonic Characterization of Composite Plates," Materials Eval., 53:1186, (1995).

18. Nondestructive Testing Handbook, Vol. 7, Ultrasonic Testing, Second Ed., ASNT, 1991, p. 841. 


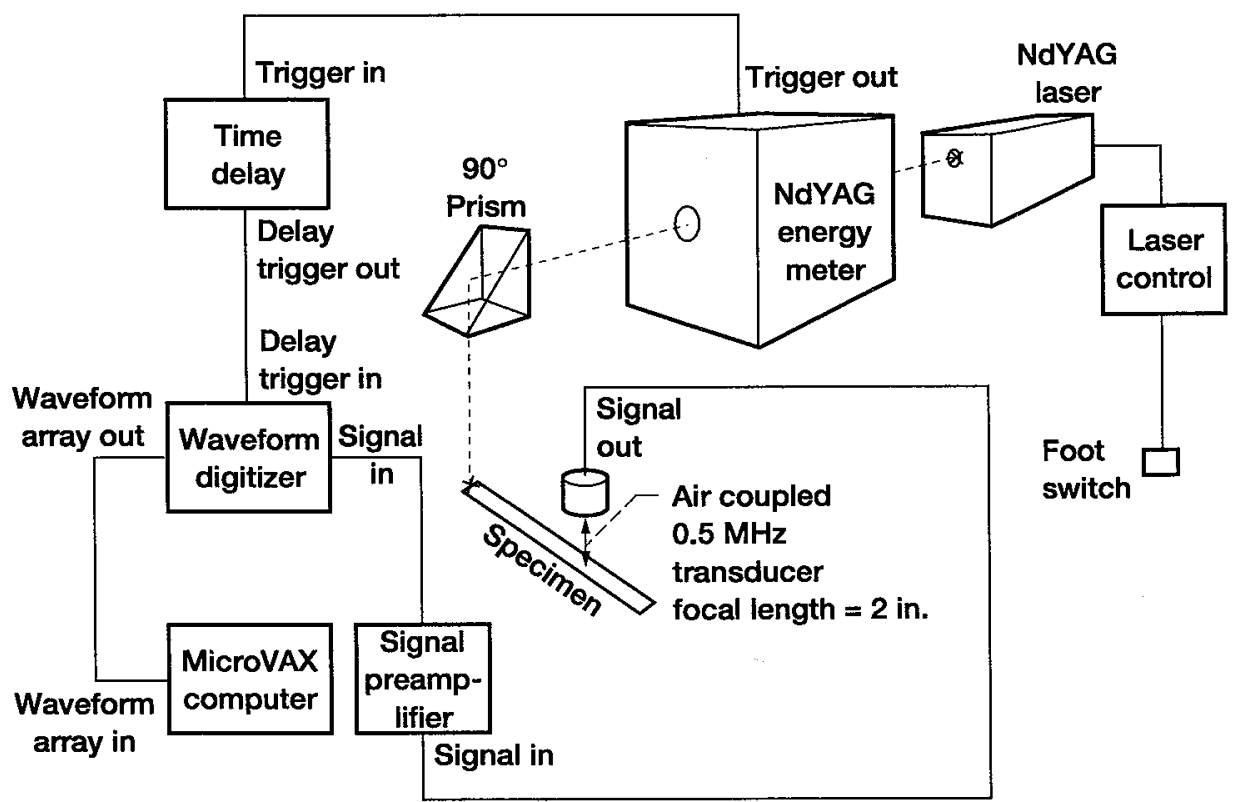

Figure 1.-Experimental arrangement for collecting laser in - air out acousto-ultrasonic waveforms.

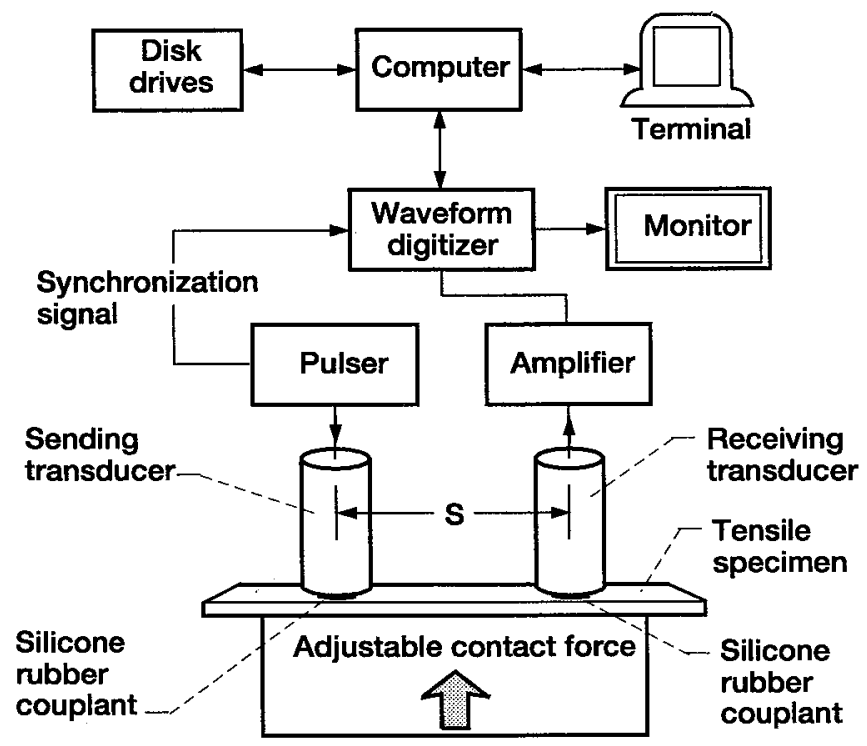

Figure 2.-Acousto-ultrasonic configuration employed for collecting data. $s$ is the centerline spacing between the transducers. $s$ is varied in these experiments. 


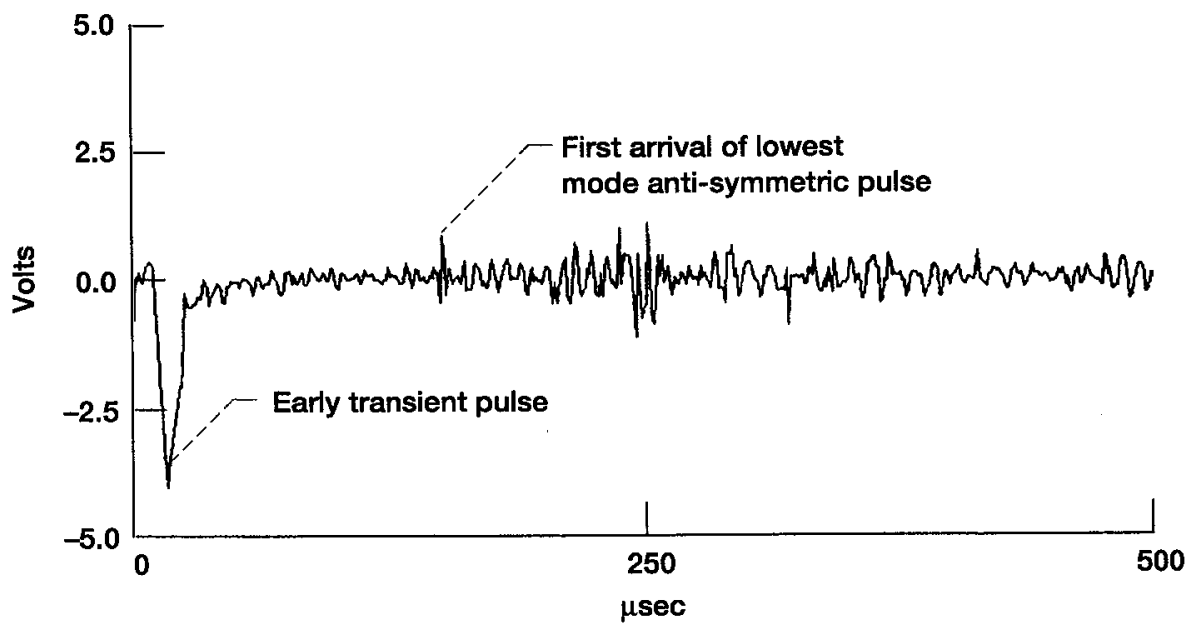

Figure 3.-Laser in - air out waveform with digitizer delay set at 0 for a $\mathrm{SiC} / \mathrm{SiC}[0 / 90]$ specimen.

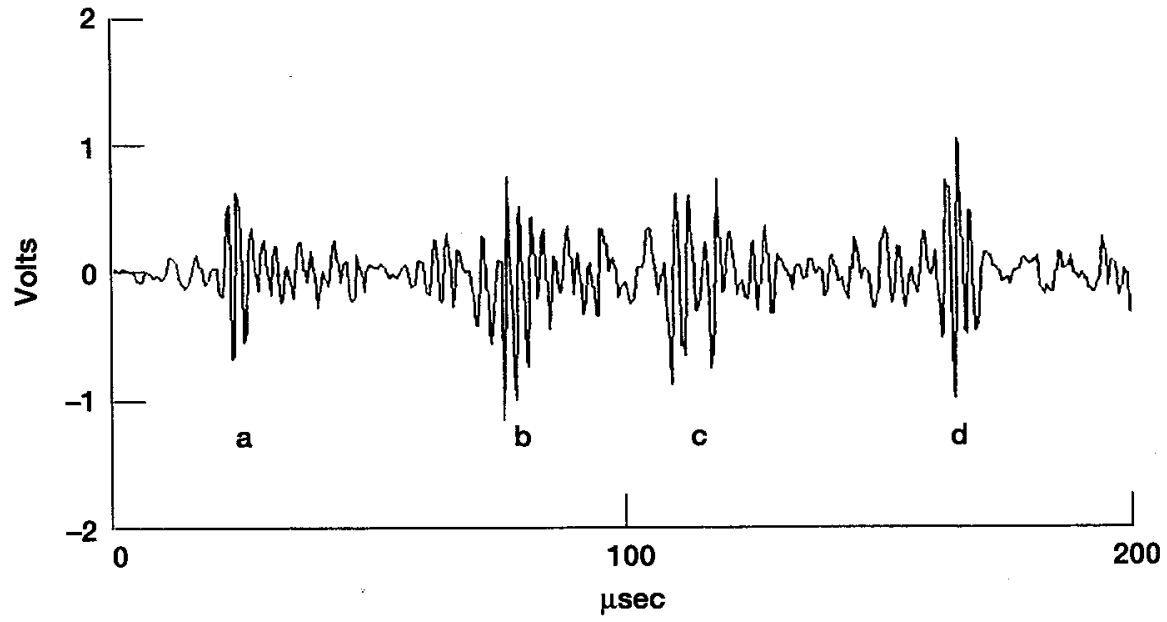

Figure 4.-Laser in - air out waveform with digitizer delay set at $125 \mu \mathrm{sec}$ for a SiC/SiC \pm 45 specimen. $a, b, c$, and d indicate four consecutive passages of the lowest antisymmetric plate pulse through the air coupled transducer focus spot. 


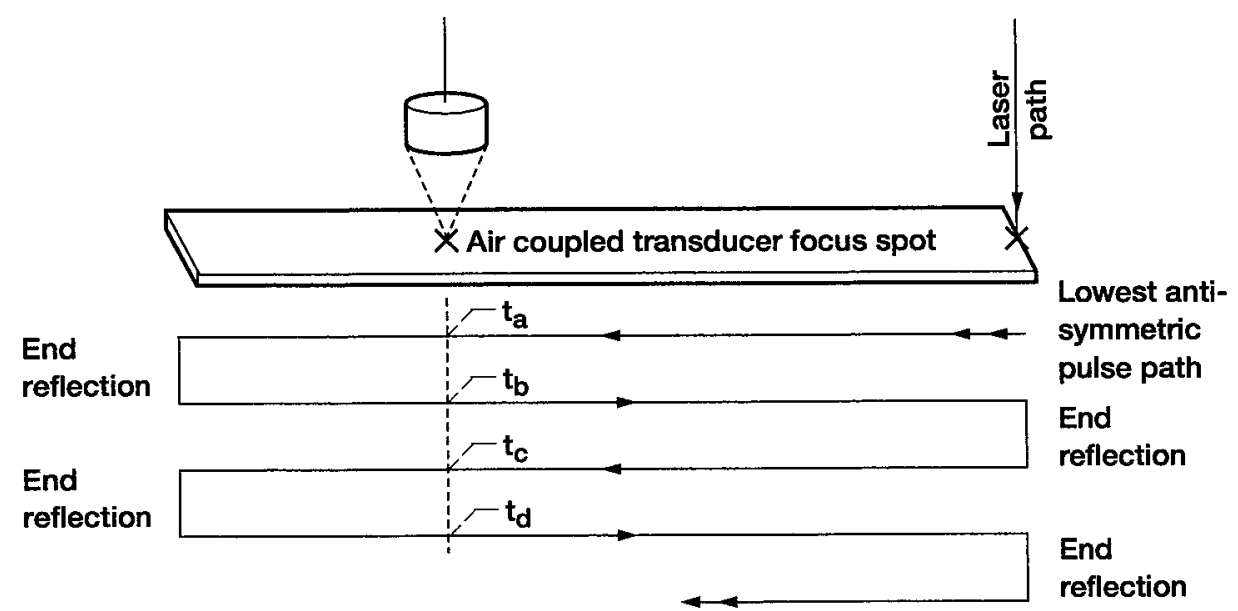

Figure 5.-Time trace of ultrasonic pulse introduced by laser.

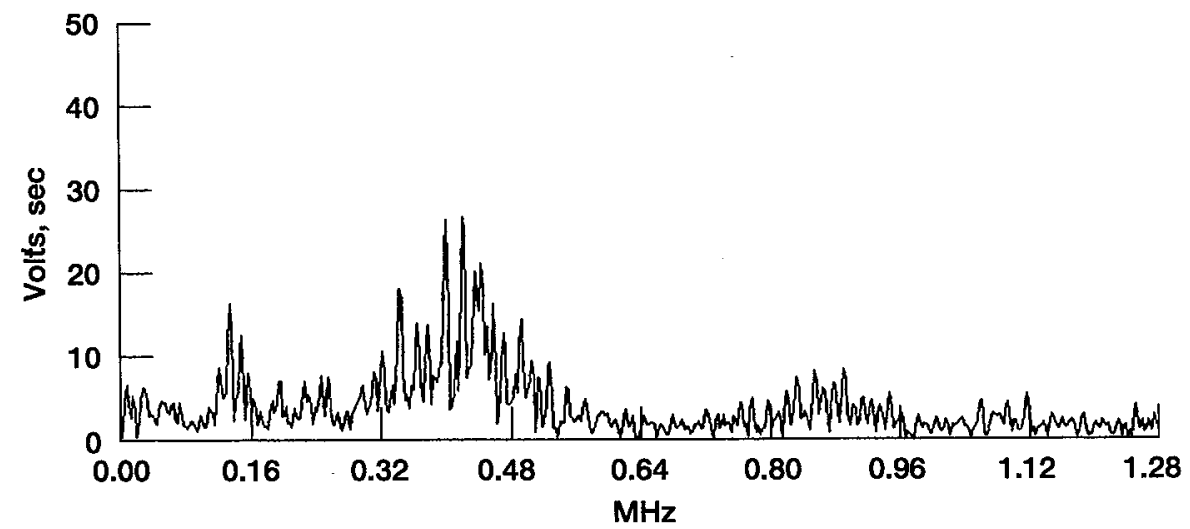

Figure 6.-Magnitude spectrum of figure 4 waveform.

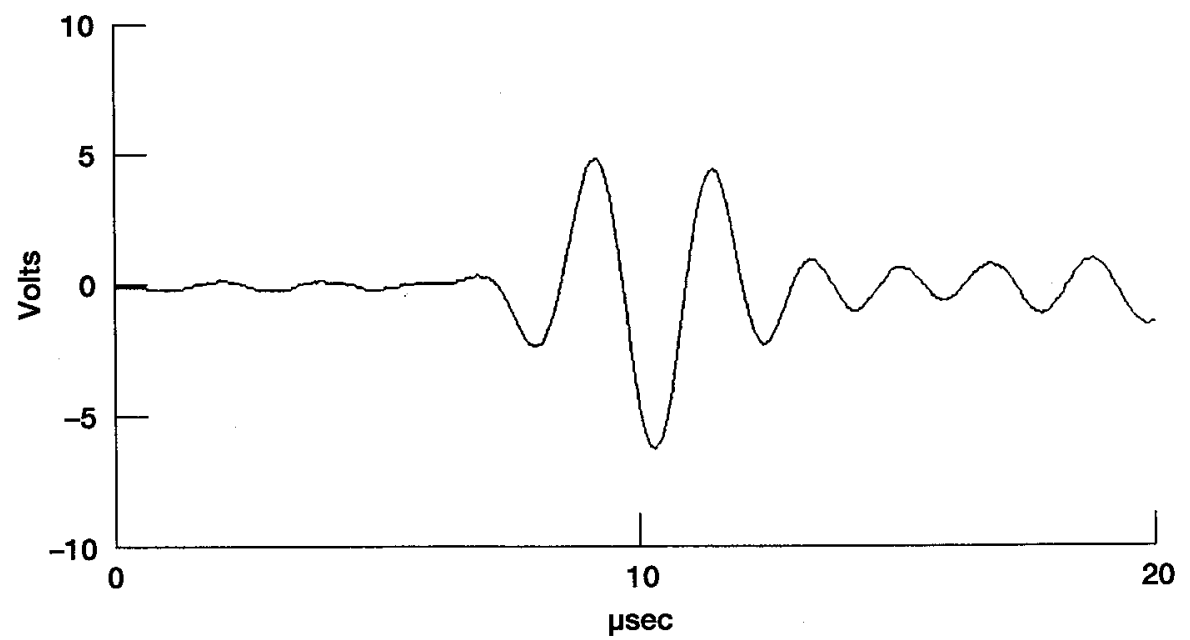

Figure 7.-Contact transducer waveform on the same SiC/SiC \pm 45 specimen as in figure 4. 

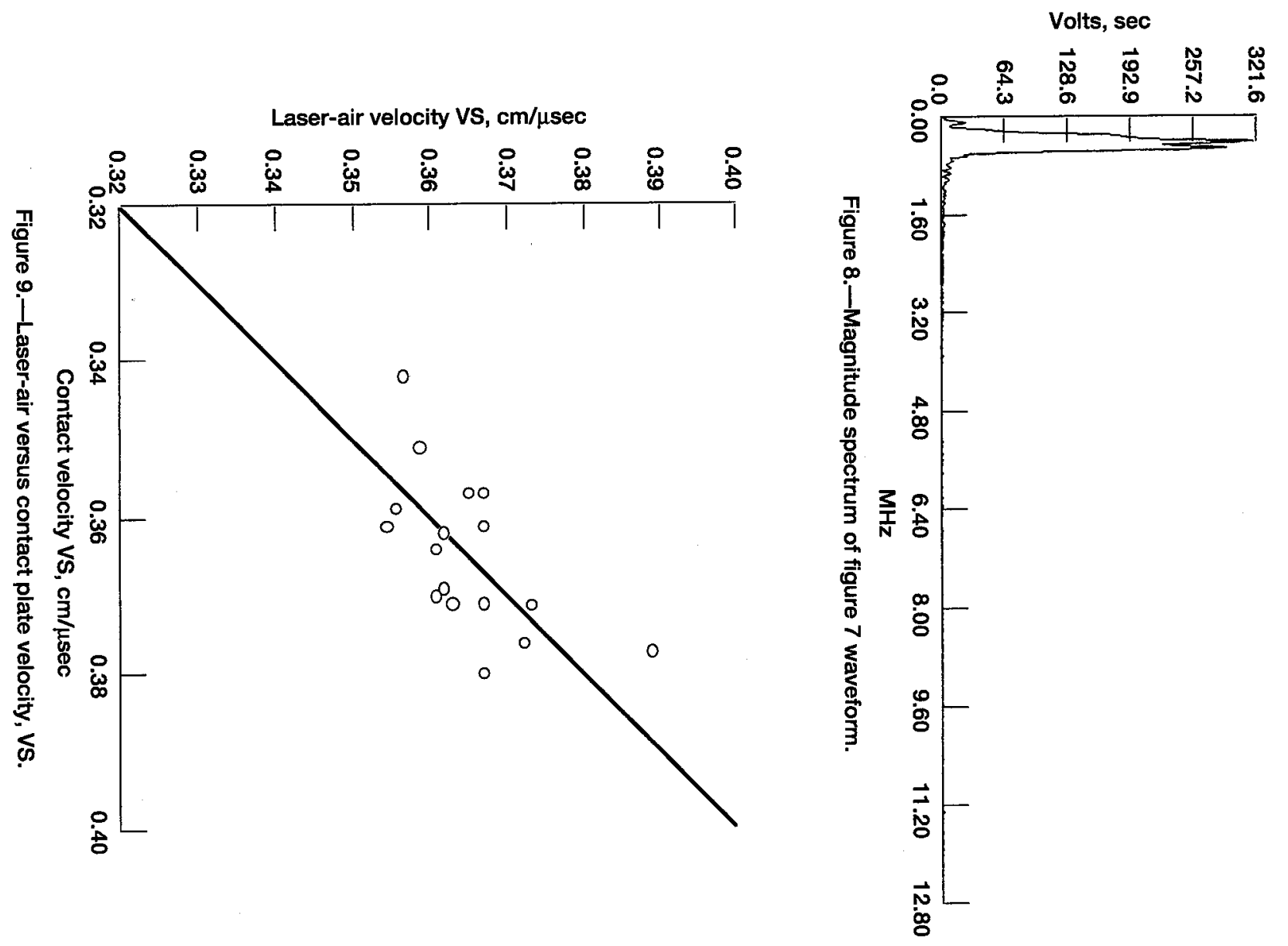
Public reporting burden tor this collection of information is estimated to average 1 hour per response, including the time for reviewing instructions, searching existing data sources. Publes of gathering an Davis Highway, Suite 1204, Arlington, VA 22202-4302, and to the Oftice of Management and Budget, Paperwork Reduction Project (0704-0188), Washington, DC 20503.

\begin{tabular}{|l|l|l|}
\hline 1. AGENCY USE ONLY (Leave blank) & $\begin{array}{c}\text { 2. REPORT DATE } \\
\text { February } 1996\end{array}$ & $\begin{array}{r}\text { 3. REPORT TYPE AND DATES COVERED } \\
\text { Technical Memorandum }\end{array}$ \\
\hline
\end{tabular}

4. TITLE AND SUBTITLE

Non-Contact Determination of Antisymmetric Plate Wave Velocity in Ceramic Matrix Composites

6. AUTHOR(S)

Harold E. Kautz

7. PERFORMING ORGANIZATTION NAME(S) AND ADDRESS(ES)

National Aeronautics and Space Administration

Lewis Research Center

Cleveland, Ohio 44135-3191

5. FUNDING NUMBERS

WU-505-63-12

9. SPONSORING/MONITORING AGENCY NAME(S) AND ADDRESS(ES)

T0. SPONSORING/MONITORING AGENCY REPORT NUMBER

National Aeronautics and Space Administration

Washington, D.C. $20546-0001$

NASA TM-107125

11. SUPPLEMENTARY NOTES

Responsible person, Harold E. Kautz, organization code 5250, (216) 433-6015.

12a. DISTRIBUTIONAVAILABILITY STATEMENT

12b. DISTRIBUTION CODE

Unclassified - Unlimited

Subject Category 38

This publication is available from the NASA Center for Aerospace Information, (301) 621-0390.

13. ABSTRACT (Maximum 200 words)

A $13 \mathrm{~mJ} \mathrm{NdYAG} 1064 \mathrm{~nm}, 4 \mathrm{~ns}$, laser pulse was employed to produce ultrasonic plate waves in 20 percent porous $\mathrm{SiC} /$ $\mathrm{SiC}$ composite tensile specimens of three different architectures. An air coupled $0.5 \mathrm{MHz}$ transducer was used to detect and collect the waveforms which contained first antisymmetric plate wave pulses for determining the shear wave velocity (VS). These results were compared to VS values determined on the same specimens with $0.5 \mathrm{MHz}$ ultrasonic transducers with contact coupling. Averages of four noncontact determinations on each of 18 specimens were compared to averages of four contact values. The noncontact VS's fall in the same range as the contact. The standard deviations for the noncontact VS's averaged 2.8 percent. The standard deviations for the contact measurements averaged 2.3 percent, indicating similar reproducibility. Repeated laser pulsing at the same location always lead to deterioration of the ultrasonic signal. The signal would recover in about $24 \mathrm{hr}$ in air however, indicating that no permanent damage was produced.

\begin{tabular}{|c|c|c|}
\hline \multicolumn{3}{|l|}{ 14. SUBJECT TERMS } \\
\hline \multicolumn{3}{|c|}{$\begin{array}{l}\text { Nondestructive testing/evaluation; Ultrasonics; Acousto-ultrasonics; Ceramic matrix } \\
\text { composites; Lasers; Air coupling transducers; Plate waves }\end{array}$} \\
\hline $\begin{array}{l}\text { 17. SECURTYY CLASSIFICATION } \\
\text { OF REPORT } \\
\text { Unclassified }\end{array}$ & $\begin{array}{l}\text { 18. SECURITY CLASSIFICATION } \\
\text { OF THIS PAGE }\end{array}$ & $\begin{array}{l}\text { 19. SECURITY CLASSIFICATION } \\
\text { OF ABSTRACT } \\
\text { Unclassified }\end{array}$ \\
\hline & & \\
\hline
\end{tabular}


National Aeronautics and

Space Administration

Lewis Research Center

\section{Brookpark Rd.}

Cleveland, $\mathrm{OH}$ 44135-3191

Official Business

Penalty for Private Use $\$ 300$

POSTMASTER: If Undeliverable - Do Not Return 